\section{POTASSIUM CHLORIDE IMPREGNATED ON ACTIVATED GREEN MUSSEL SHELLS (KCL/AGMS): AN ACTIVE CATALYST TOWARDS KNOEVENAGEL CONDENSATION}

\author{
Bayu Ardiansah*, Ridla Bakri, Yudis Ananda Putra
}

Department of Chemistry, FMIPA, Universitas Indonesia, 16424, Depok, Indonesia Depok, Indonesia
Article history

Received

11 October 2018

Received in revised form

18 March 2019

Accepted

2 April 2019

Published online

25 June 2019

*Corresponding author bayu.ardiansah@sci.ui.ac.id

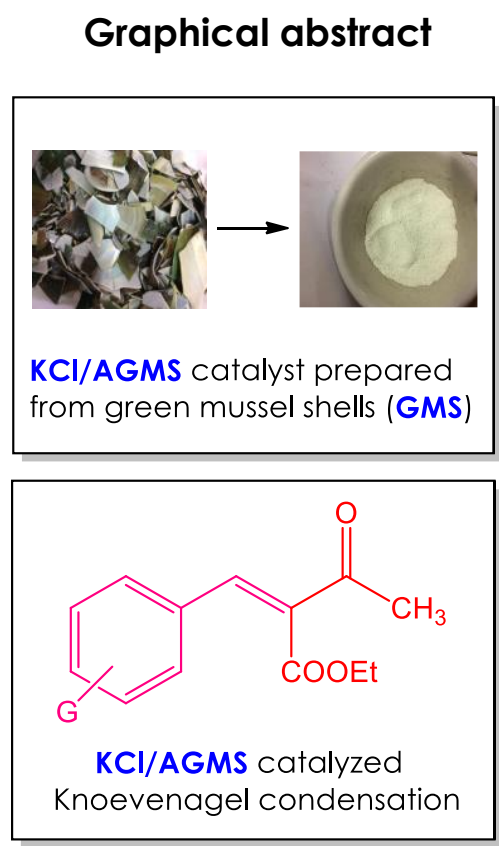

\begin{abstract}
Knoevenagel condensation represents one of the most important $\mathrm{C}-\mathrm{C}$ bond forming reactions in organic chemistry. The typical reaction was carried out commonly in the presence of homogeneous acid as well as basic catalysts. With the problems like corrosive and high catalyst amount, the search for a new heterogeneous catalyst is an attractive research topic in this area. $\mathrm{KCl}$ supported on activated green mussel shell (KCl/AGMS) was prepared by impregnation method and characterized by some analytical instrumentations (IR, XRD, SEM, EDAX). The prepared materials shows an incredible catalytic ability in Knoevenagel condensation of ethyl acetoacetate with aromatic aldehydes to produce condensed products $3 a-3 d$ in medium to good yields (60-94\%). The findings disclose a mild route for the synthesis of Knoevenagel products using a cost-effective and green catalyst.
\end{abstract}

Keywords: Green mussel shell, KCl/AGMS, solid catalyst, Knoevenagel condensation

(C) 2019 Penerbit UTM Press. All rights reserved

\subsection{INTRODUCTION}

Knoevenagel condensation is a reaction between aromatic aldehydes/ ketones with active methylene compounds containing electron-withdrawing group [1]. It is an important organic reaction involving the formation of C-C double bond [1,2], and has been widely used for production of various fine chemicals and construction of heterocyclic system such as coumarins, indoles and pyranopyrazoles [3-7]. Recently, Knoevenagel condensation was also developed as a testing reaction to evaluate the catalytic performance of novel solid acid and base catalysts [8-11].

In common, many Knoevenagel condensation were carried out in the presence of homogeneous catalysts such as aliphatic and cyclic amines, indium(III), and ionic liquids [12-16]. In despite of their appreciable catalytic performance, the uncomfort issues in relation with separation and recycling procedures of the catalysts can not deal the growing request on clean and sustainable catalysis today [17]. Furthermore, corrosivity and requirement of high stoichiometric amount of the catalysts make them difficult to be applied in industrial scale. 
<smiles>[14CH3]C=O</smiles>

1

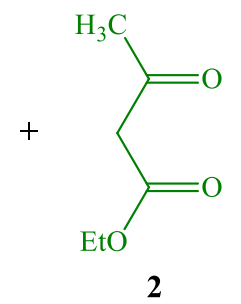

2
Figure 1

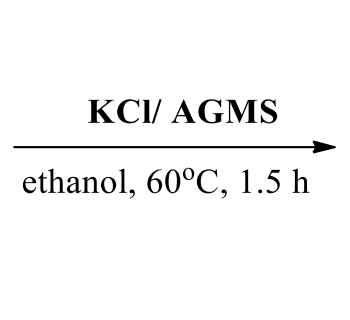

3a: $\mathrm{Ar}=\mathrm{Ph}-$

3b: $\mathrm{Ar}=4-\mathrm{OH}-\mathrm{Ph}-$

3c: $\mathrm{Ar}=3-\mathrm{OMe}-\mathrm{Ph}-$

3d: $\mathrm{Ar}=4-\mathrm{OH}-3-\mathrm{OMe}-\mathrm{Ph}-$

3a-d

Then, several studies have been focused on the utilization of solid base catalysts, such as $\mathrm{g}^{-} \mathrm{C}_{3} \mathrm{~N}_{4}$ [18], Ca-containing mesoporous silica [19], hydroxyapatite supported cesium carbonate [20], methylated $\mathrm{N}$ substituted SBA-15 [21] and Mg-doped graphitic carbon nitride [22]. Amine-grafted on lanthanide MOF [23] and amine-functionalized sugarcane bagasse [24] have also been employed. In addition, other solid catalysts like hydrotalcites [25], polymer microgel particles [26], and basic zeolites [27] were also well-to-do of catalyzing Knoevenagel condensation reaction. However, several of these methods have drawbacks like harmful reaction processes, low yield, toxic solvents, long reaction time and need of high reaction temperature. Thus, there is still a struggle for the development of mild protocols to carry out Knoevenagel condensation under green chemistry and simple work-up methods.

The material synthesized from the waste shells opens window for renewable catalyst and at the same time reutilize the waste gererated. Previously, mussel shells have been explored for some purpose, such as catalyst in biodiesel synthesis [28], mercury removal [29] and effective biosorbent to absorb textile dyes from aqueous solution [30]. In this work, preparation and characterization of potassium chloride supported on activated green mussel shells (KCl/ AGMS) will be studied. Moreover, the catalytic capability of prepared material in Knoevenagel condensation will be noticed (Figure 1).

\subsection{METHODOLOGY}

\subsection{General and Instrumentation}

Ethyl acetoacetate and benzaldehyde derivatives were purchased from Merck and Sigma-Aldrich. Solvents and other chemicals were purchased from commercial suppliers. IR spectra were recorded on ShimadzU Prestige 21 FTIR spectrophotometer. SEM was performed with a SATW (CM-200, Phillips) tandem EDAX instrument. X-ray diffraction (XRD) patterns were recorded on a Phillips-1710 X-ray diffractometer with Cu-Ka $(0.154 \mathrm{~nm})$ radiation in the range 2 theta degree of $0-90^{\circ}$. All reactions were monitored by thin layer chromatography (TLC) using silica coated on alumina plates. Mass analysis was conducted on a Shimadzu QP Mass spectrometer $2010 \mathrm{~A}$ with $70 \mathrm{eV}$ electron ionization potential.

\subsection{Preparation of $\mathrm{KCl} / \mathrm{AGMS}$ Catalyst}

Collected from household waste, empty natural green mussel shells (NGMS) were then washed with warm tap-water. The NGMS was washed with deionized water and dried at $120^{\circ} \mathrm{C}$ for $2 \mathrm{~h}$. It was then grinded until get rough powders using an ordinary mortar and pestle. The GMS was calcined at $900^{\circ} \mathrm{C}$ for $4 \mathrm{~h}$. The resulting material was denoted by activated green mussel shells (AGMS). Subsequently, $\mathrm{KCl} / \mathrm{AGMS}$ catalyst was prepared using a wet impregnation method with modification of a reported work [31]. Typically, $5 \mathrm{~g}$ of AGMS was slowly immersed into $25 \mathrm{ml}$ of aqueous solution containing $2.5 \mathrm{~g}$ of $\mathrm{KCl}$ with continuous stirring at room temperature for $3 \mathrm{~h}$. The resulting white slurry was dried in an ordinary oven at $100^{\circ} \mathrm{C}$ for $2 \mathrm{~h}$. Finally, the solid was calcined at $500^{\circ} \mathrm{C}$ for $3 \mathrm{~h}$ in air environment and this product was denoted as $\mathrm{KCl} / \mathrm{AGMS}$.

\subsection{Procedure for Knoevenagel Condensation}

To find the optimized conditions for Knoevenagel condensation, we explore the reaction between benzaldehyde and ethyl acetoacetate. Typically, benzaldehyde $(2 \mathrm{mmol})$, ethyl acetoacetate $(2$ $\mathrm{mmol})$ and ethanol $(5 \mathrm{ml})$ were stirred in the presence of various catalyst amount. Temperature and reaction time were also varied. After completion lobserved by thin layer chromatography with nhexane: ethyl acetate 7:3 as elvent), hot ethanol was added into the reaction mixture. The mixture was filtered, and filtrate was evaporated under reduced pressure to give the solid product, (Z)-ethyl 2benzylidene-3-oxobutanoate (3a). For the synthesis of Knoevenagel products using benzaldehyde derivatives, we used the optimized conditions obtained from model reaction.

\subsubsection{Spectral Data of Compound 3a: (Z)-ethyl 2-} benzylidene-3-oxobutanoate

Yellow solid; IR (KBr, $\left.\mathrm{cm}^{-1}\right) 3050$ (C-H sp2 stretching), 3000-2970 (C-H sp ${ }^{3}$ stretching), 1660-1640 (C=O stretching), 1510 ( $\mathrm{C}=\mathrm{C}$ aromatic), 1450-1430 (C-H sp ${ }^{3}$ bending), 1226 (C-O stretching); MS (m/z) $218.0\left(\mathrm{M}^{+}\right)$, 
$217.0\left([\mathrm{M}-1]^{+}\right), 190.9,173.0,155.1,131.0,103.0,77.1$, 43.1.

2.3.2 Spectral Data of Compound 3b: (Z)-ethyl 2-(4hydroxybenzylidene)-3-oxobutanoate

Yellow solid, IR ( $\left.\mathrm{KBr}, \mathrm{cm}^{-1}\right) 3205$ (O-H stretching), 3051$3020 \quad\left(\mathrm{C}-\mathrm{H} \quad \mathrm{sp}^{2}\right.$ stretching), 2950-2880 (C-H sp 3 stretching), 1750 ( $\mathrm{C}=\mathrm{O}$ stretching), 1610 ( $\mathrm{C}=\mathrm{C}$ olefinic stretching), 1500-1480 ( $\mathrm{C}=\mathrm{C}$ aromatic), 1256 (C-O stretching); $M S(\mathrm{~m} / \mathrm{z}) 234.0\left(\mathrm{M}^{+}\right), 221.0,209.9,207.0$ $190.9,176.8,162.9,146.9,120.9,95.9,73.0,59.0,44.0$.

2.3.3 Spectral Data of Compound 3c: (Z)-ethyl 2-(3methoxybenzylidene)-3-oxobutanoate

Yellow solid, IR (KBr, $\left.\mathrm{cm}^{-1}\right) \quad 3040-3000$ (C-H sp stretching), 2950-2800 (C-H sp3 stretching), 1750 and 1720 ( $C=O$ stretching), 1605 ( $C=C$ olefinic stretching), 1501-1490 (C=C aromatic), 1220 (C-O stretching); MS $(\mathrm{m} / \mathrm{z}) 248.1\left(\mathrm{M}^{+}\right), 217.0,161.0,102.0,43.1$.

2.3.4 Spectral Data of Compound 3d: (Z)-ethyl 2-(4hydroxy-3-methoxybenzylidene)-3-oxobutanoate

Yellow solid, IR ( $\left.\mathrm{KBr}, \mathrm{cm}^{-1}\right)$ 3400-3200 (O-H stretching), 3100-3000 (C-H sp2 stretching), 2963-2820 (C-H sp stretching), $1720-1700 \quad(\mathrm{C}=\mathrm{O}$ stretching), $1612 \quad(\mathrm{C}=\mathrm{C}$ olefinic stretching), 1503 (C=C aromatic), 1450-1400 (C-H sp ${ }^{3}$ bending vibration), 1150 (C-O stretching); MS (m/z) $264.0\left(\mathrm{M}^{+}\right), 252.9,206.9,190.9,155.9,132.9$, 96.0, 73.0, 44.0.

\subsection{RESULT AND DISCUSSION}

\subsection{Characterization of $\mathrm{KCl} / \mathrm{AGMS}$}

Nowadays, the utilization of waste materials as source of heterogeneous catalysts has been of interest in the development of sustainable catalytic processes [32]. Waste materials containing calcium carbonate are renewable [33], and they are often used as substrates to produce calcium oxide, a promising catalyst that are being used in various organic transformation [34-40]. Natural Green mussel shell (NGMS) was chosen as source of $\mathrm{CaO}$ because it mainly consists of calcium carbonate [28].

To analyze the functional groups, FT-IR spectrophotometry was applied in this work. NGMS in Figure 2(a) shows two major bands around 3600-3000 and $1485 \mathrm{~cm}^{-1}$. The broad peak at $3600-3000 \mathrm{~cm}^{-1}$ is assigned to the stretching mode of $\mathrm{O}-\mathrm{H}$ group in residual water molecule, while the band at $1485 \mathrm{~cm}^{-1}$ is associated with $\mathrm{CO}_{3}{ }^{2-}$ stretching vibration in $\mathrm{CaCO}_{3}$. To confirm the functional groups on GMS and AGMS, we collected the FT-IR spectra and compared them. After thermal treatment, there is the detection of the $3650 \mathrm{~cm}^{-1}$ sharp band attributable to hydroxyl group due to surface interaction of water molecule with AGMS sample. Broadband around
$600-400 \mathrm{~cm}^{-1}$ indicating the presence of $\mathrm{Ca}-\mathrm{O}$ stretching vibration [36]. These peaks appeared after NGMS was calcined at $900^{\circ} \mathrm{C}$. Identical FT-IR spectra between AGMS and $\mathrm{KCl} / \mathrm{AGMS}$ indicating the same chemical functionalities in both samples.
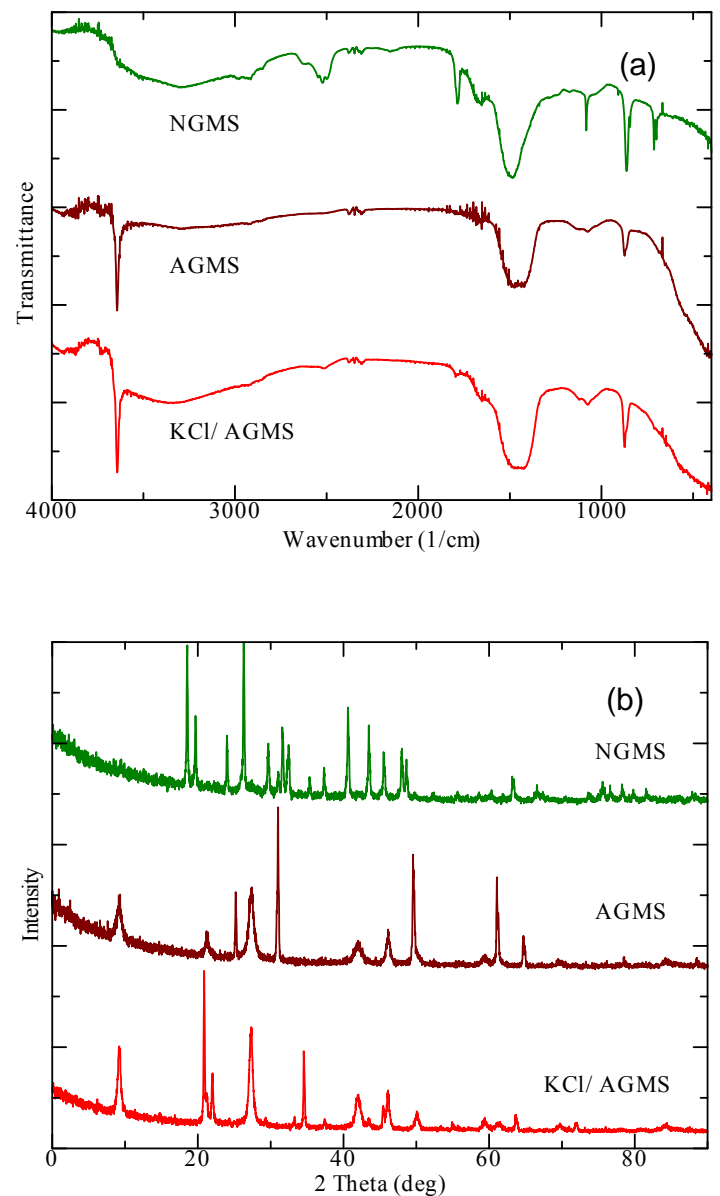

Figure 2 (a) FTIR and (b) XRD spectra of catalyst derived from natural green mussel shells (NGMS)

$\mathrm{CaCO}_{3}$ content in NGMS was in the range of $95-$ $99 \%$ [41]. XRD results in Figure 2(b) reveal the composition of NGMS mainly consists of $\mathrm{CaCO}_{3}$ in the form of vaterite phase, as indicated by strong diffraction peaks at $2 \theta$ of 24.6 and $27.0 \circ$ [42-44]. The AGMS displayed peaks indicating the presence of $\mathrm{CaO}\left(2 \theta\right.$ at $\left.32.2^{\circ}\right)$ and $\mathrm{Ca}(\mathrm{OH})_{2}\left(2 \theta\right.$ at 28.7 and $\left.34.1^{\circ}\right)$ phases [45]. After impregnation with $\mathrm{KCl}$ and recalcination at $500^{\circ} \mathrm{C}$ for $3 \mathrm{~h}$, peaks corresponding to $\mathrm{KCaCl}_{3}\left(2 \theta\right.$ at $\left.28.4^{\circ}\right)$ and $\mathrm{Ca}(\mathrm{OH})_{2}\left(2 \theta\right.$ at $\left.34.1^{\circ}\right)$ were produced, associated with small $\mathrm{CaO}$ peaks in $\mathrm{KCl}$ /AGMS catalyst [31]. 


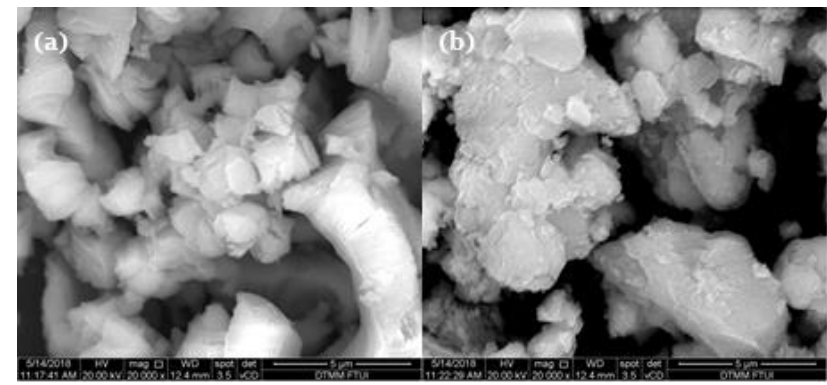

Figure 3 SEM images of (a) AGMS and (b) KCl/ AGMS

The microstructure of $A G M S$ and $\mathrm{KCl} / \mathrm{AGMS}$ is shown in Figure 3. As investigated before, a typical layered architecture is the characteristic for mussel shells [46]. With calcination temperature at $900^{\circ} \mathrm{C}$, the morphology changed to porous structure. The morphology conforms to those reported by Buasri et al. [28] and Hu et al. 47]. The AGMS shape was irregular, and some of them attracted together to form aggregates. After potassium chloride impregnation, the $\mathrm{KCl} / \mathrm{AGMS}$ catalyst possess porous structure with large grains. $\mathrm{KCl}$ particles were observed in the surface of AGMS. Since AGMS and $\mathrm{KCl} / \mathrm{AGMS}$ materials are less-porous, the particle size should directly correspond to surface area [28].

The elemental compositions of the AGMS and $\mathrm{KCl} / \mathrm{AGMS}$ catalyst were studied by energy dispersive $X$-ray spectroscopy (EDS). It confirms that the AGMS was composed of $\mathrm{Ca}, \mathrm{O}$ and $\mathrm{C}$ (Figure 4a). The amounts of $\mathrm{Ca}$ and $\mathrm{O}$ in the AGMS are found to be 35.36 and $58.71 \mathrm{w}+\%$, respectively. Existence of $C$ in EDS spectrum may due to the presence of uncalcined calcium carbonate in the AGMS sample. The EDS analysis of the $\mathrm{KCl} / \mathrm{AGMS}$ indicated that the $\mathrm{K}$ and $\mathrm{Cl}$ content are 16.78 and $15.37 \mathrm{wt \%}$. The result revealed the successive impregnation process.

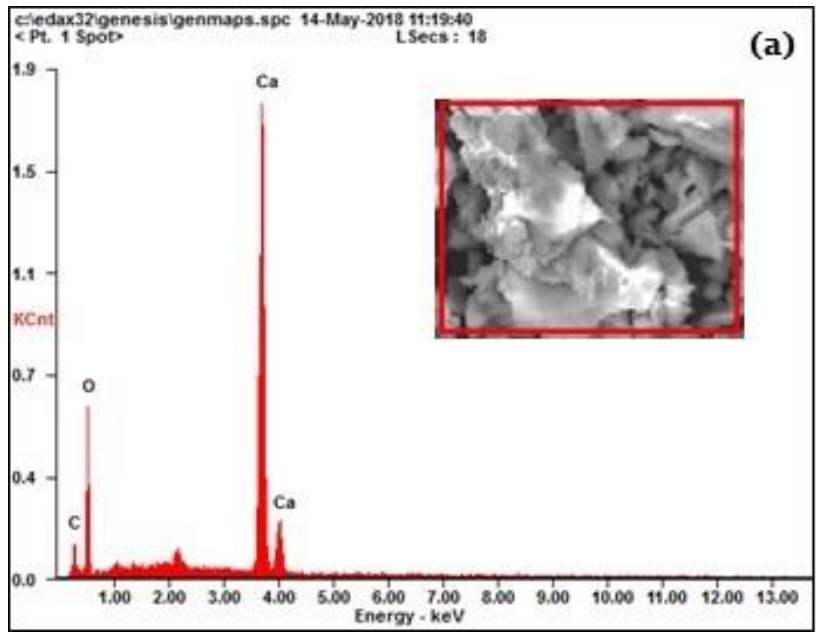

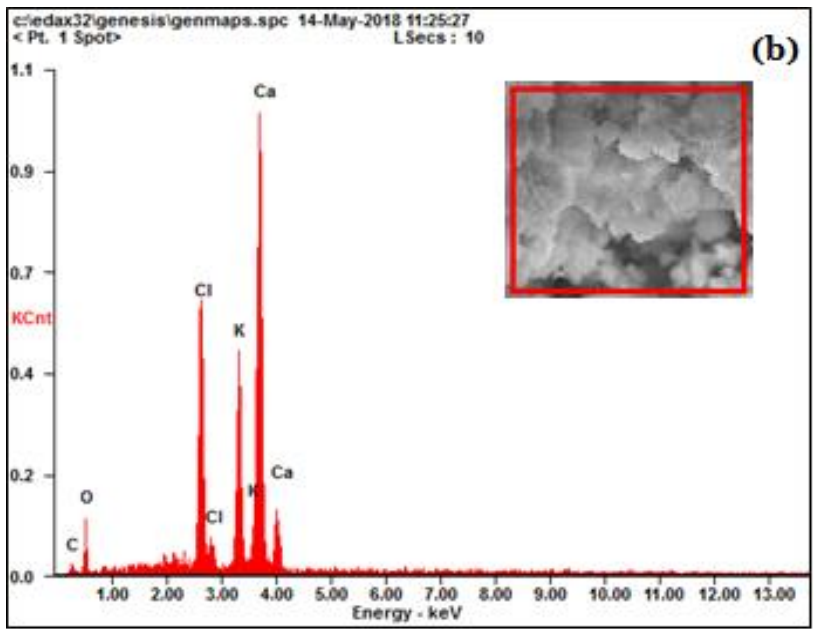

Figure 4 EDS spectra of (a) AGMS and (b) $\mathrm{KCl} / \mathrm{AGMS}$

\subsection{Knoevenagel Condensation}

Knoevenagel condensation has been considered as one of the most important reactions for producing carbonyl compounds integrated with $\mathrm{C}=\mathrm{C}$ double bond and generally contains aromatic functionalities [48]. In this work, we explored the ability of $\mathrm{KCl}$ /AGMS for Knoevenagel condensation reaction between ethyl acetoacetate and benzaldehyde derivatives. For initial investigation of optimized conditions, benzaldehyde and ethyl acetoacetate are used as model substrates.

A series of experiments were conducted for $1.5 \mathrm{~h}$ at room temperature and at $60^{\circ} \mathrm{C}$ in the absence of catalyst, which yields of product were isolated in trace (Table 1 Entry 1 and 2). The use of AGMS catalyst at room temperature and $1.5 \mathrm{~h}$ in the reaction generating $60 \%$ yield only (Table 1 Entry 6). The reaction furnished the highest yield up to $94 \%$ in the presence of $15 \mathrm{w}+\%$ of $\mathrm{KCl} / \mathrm{AGMS}$ at $60^{\circ} \mathrm{C}$ for $1.5 \mathrm{~h}$ (Table 1 Entry 7). The use of $20 \mathrm{w}+\%$ of catalyst under same conditions only give $86 \%$ yield (Table 1 Entry 8 ). To further verify the influence of temperature, the reaction was carried out at three different temperature. The increase of temperature up to $80^{\circ} \mathrm{C}$ did not affect any increase of product yield (Table 1 Entry 9). 
Table 1 Optimization in Knoevenagel condensation using $\mathrm{KCl} / \mathrm{AGMS}$ heterogeneous catalyst

\begin{tabular}{|c|c|c|c|c|}
\hline Entry & $\begin{array}{c}\text { Catalyst } \\
(w t \%)\end{array}$ & $\mathrm{T}\left({ }^{\circ} \mathrm{C}\right)$ & $\begin{array}{c}\text { Time } \\
\text { (h) }\end{array}$ & $\begin{array}{c}\text { Yield b } \\
(\%)\end{array}$ \\
\hline 1 & - & 60 & 1.5 & Trace \\
\hline 2 & - & $\mathrm{R} \dagger$ & 1.5 & Trace \\
\hline 3 & 5 & 60 & 1.5 & 20 \\
\hline 4 & 10 & 60 & 1.5 & 57 \\
\hline 5 & 15 & R† & 3 & 80 \\
\hline 6 & $15^{a}$ & R† & 1.5 & 60 \\
\hline 7 & 15 & 60 & 1.5 & 94 \\
\hline 8 & 20 & 60 & 1.5 & 86 \\
\hline 9 & 20 & 80 & 1.5 & 88 \\
\hline
\end{tabular}

Encouraged by the aforementioned results, Knoevenagel condensation of some aromatic aldehydes with ethyl acetoacetate catalyzed by $\mathrm{KCl} / \mathrm{AGMS}$ in ethanol have been explored. As can be seen in Table 2, all products were obtained in good yields. The IR data of condensation products showed peak around 1610-1620 $\mathrm{cm}^{-1}$ indicating the existence of $\mathrm{C}=\mathrm{C}$ olefinic group. Broad absorption band in the range of $3000-3600 \mathrm{~cm}^{-1}$ is found in the IR spectra of compound $3 a, 3 b$ and $3 d$, which is corresponds to the presence of hydroxyl group. Meanwhile, in IR spectrum data of compound $3 \mathrm{c}$, there is no peak for $\mathrm{OH}$ group. The peak for $\mathrm{sp}^{3} \mathrm{C}-\mathrm{H}$ and $\mathrm{C}=\mathrm{C}$ stretching can clearly be seen. Mass spectra measurements were done to elucidate the condensation products with specific molecular cation peaks in their spectra.

Table 2 Knoevenagel condensation of benzaldehyde derivatives

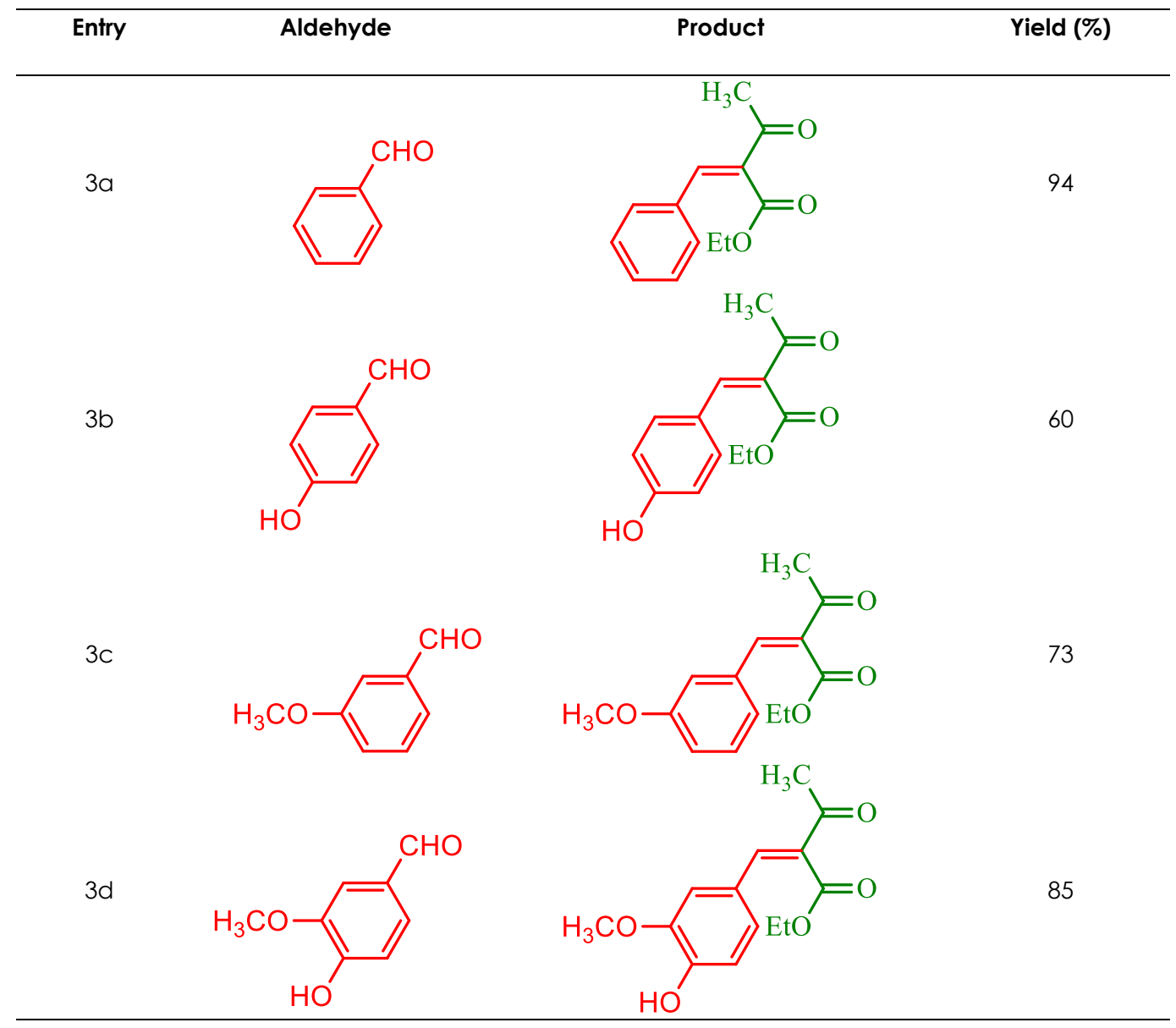

Reaction conditions: $\mathrm{KCl} / \mathrm{AGMS}$ catalyst $15 \mathrm{w}+\%$, at $60^{\circ} \mathrm{C}, 1.5 \mathrm{~h}$ reaction time, in ethanol.

The proposed mechanism of Knoevenagel condensation is stated below (Figure 5). KCl/AGMS is CaO-based material and considered as base catalyst. The catalyst will deprotonate methylene group of ethyl acetoacetate to give enolate ion. Then it will undergo nucleophilic addition with benzaldehyde. After protonation, a typical $\beta$-hydroxy carbonyl is obtained. In the final step, dehydration of this intermediate will give Knoevenagel product. 


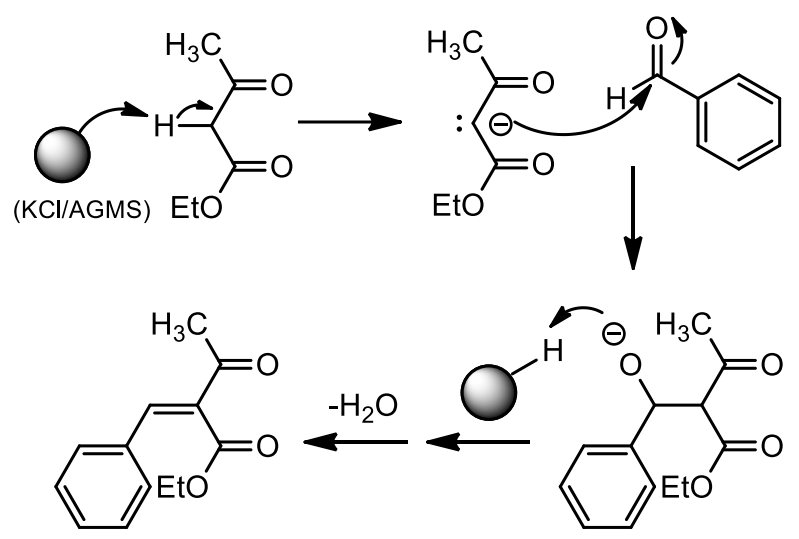

Figure 5 Proposed mechanism of this Knoevenagel condensation

\subsection{CONCLUSION}

In conclusion, $\mathrm{KCl} / \mathrm{AGMS}$ solid base catalyst has been succesfully prepared from green mussel shells waste by thermal activation then wet impregnation method. The impregnated $\mathrm{KCl}$ into AGMS was confirmed by EDAX spectroscopy. We have established a simple catalyst for C-C bond construction via Knoevenagel condensation reaction having high activity to generate products in good yields.

\section{Acknowledgement}

This work was fully supported by Universitas Indonesia through PITTA Grant 2017 with contract No. 676/UN2.R3.1/HKP.05.00/2017.

\section{References}

[1] Tangale, N. P., Sonar, S. K., Niphadkar, P. S., and Joshi, P. N. 2016. Hierarchical K/LTL zeolites: Synthesis by Alkali Treatment, Characterization and Catalytic Performance in Knoevenagel Condensation Reaction. Journal of Industrial and Engineering Chemistry. 40: 128-136.

[2] Sakthivel, B. and Dhakshinamoorthy, A. 2017. Chitosan as a Reusable Solid Catalyst for Knoevenagel Condensation Reaction. Journal of Colloid and Interface Science. 485: 75-80.

[3] Veloso, C. O., Henriques, C. A., Dias, A. G., de Lima, E. C., Souza, B. M. and Monteiro, J. L. F. 2011 . A Green Synthesis of a, $\beta$-unsaturated Carbonyl Compounds from Glyceraldehyde Acetonide. Quimica Nova. 34(4): $617-$ 620.

[4] Ren, Y. M. and Cai, C. 2007. Knoevenagel Condensation of Aromatic Aldehydes with Active Methylene Compounds using a Catalytic Amount of lodine and $\mathrm{K}_{2} \mathrm{CO}_{3}$ at Room Temperature. Synthetic Communication. 37: 2209-2213.

[5] Phadtare, S.B. and Shankarling, G.S. 2012. Greener Coumarin Synthesis by Knoevenagel Condensation using Biodegradable Choline Chloride. Environmental Chemistry Letters. 10: 363-368.
[6] Heaner, W. L., Gelbaum, C. S., Gelbaum, L., Pollet, P., Richman, K. W., DuBay, W., et al. 2013. Indoles via Knoevenagel-Hemetsberger Reaction Sequence. RSC Advances. 3: 13232-13242.

[7] Sinija, P. S. and Sreekumar, K. 2015. Facile Synthesis of Pyranopyrazoles and 3,4-dihydropyrimidin-2(1H)-ones by a Ti-grafted Polyamidoamine Dendritic Silica Hybrid Catalyst Via a Dual Activation Route. RSC Advances. 5: 101776101788.

[8] Mangala, K. and Sreekumar, K. 2012. PolycarbosilaneSupported Titanium (IV) Catalyst for Knoevenagel Condensation Reaction. Applied Organometallic Chemistry. 27: 73-78.

[9] Schejn, A., Mazet, T., Falk, V., Balan, L., Aranda, L., Medjahdi, G. and Schneider, R. 2015. Fe $\mathrm{O}_{4} @ \mathrm{ZIF}-8$ : Magnetically Recoverable Catalysts by Loading $\mathrm{Fe}_{3} \mathrm{O}_{4}$ Nanoparticles inside a Zinc Imidazolate Framework. Dalton Transaction. 44: 10136-10140.

[10] Wach, A., Drozdek, M., Dudek, B., Biazik, M., Latka, P., Michalik, M. and Kustrowski, P. 2015. Differences in Catalytic Activity of Poly(vinylamine) Introduced on Surface of Mesoporous SBA-15 by Grafting from and Grafting onto Method in Knoevenagel Condensation. 119(34): 19954-19966.

[11] Perez, C. N., Monteiro, J. L. F., Nieto, J. M. L. and Henriques, C. A. 2009. Influence of Basic Properties of Mg Al-mixed Oxides on Their Catalytic Activity in Knoevenagel Condensation between Benzaldehyde and Phenylsulfonylacetonitrile. 32(9): 2341-2346.

[12] Pawar, H. S., Wagh, A. S. and Lali, A. M. 2016. Triethylamine: A Potential N-base Surrogate for Pyridine in Knoevenagel Condensation of Aromatic Aldehydes and Malonic Acid. New Journal of Chemistry. 40: 4962-4968.

[13] Dalessandro, E. V., Collin, H. P., Guimaraes, L. G. L. and Pliego, M. S. V. R. 2017. Mechanism of the Piperidinecatalyzed Knoevenagel Condensation Reaction in Methanol: The Role of Iminium and Enolate Ions. The Journal of Physical Chemistry B. 121 (20): 5300-5307.

[14] Ogiwara, Y., Takahashi, K., Kitazawa, T. and Sakai, N. 2015. Indium (III)-catalyzed Knoevenagel Condensation of Aldehydes and Activated Methylenes Using Acetic Anhydride as a Promoter. The Journal of Organic Chemistry. 80(6): 3101-3110.

[15] Gao, G.-H., Lu, L., Zou, T., Gao, J.-B., Liu, Y. and He, M.-Y. 2007. Basic Ionic Liquid: A Reusable Catalyst for Knoevenagel Condensation in Aqueous Media. Chemical Research in Chinese Universities. 23(2): 169-172.

[16] Player, L. C., Chan, B., Turner, P., Masters, A. F. and Maschmeyer, T. 2018. Bromozincate Ionic Liquids in the Knoevenagel Condensation Reaction. Applied Catalysis B: Environmental. 223: 228-233.

[17] XU, J., Shen, K., Xue, B. and Li, Y.-X. 2013. Microporous Carbon Nitride as an Effective Solid Base Catalyst for Knoevenagel Condensation Reactions. Journal of Molecular Catalysis A: Chemical. 372: 105-113.

[18] Sharma, P. and Sasson, Y. 2017. Highly Active g-C3N4 as a Solid Base Catalyst for Knoevenagel Condensation Reaction under Phase Transfer Condition. RSC Advances. 7: 25589-25596.

[19] Ikeve, K., Miyoshi, N., Tanaka, T. and Machida, M. 2011. Ca-containing Mesoporous Silica as a Solid Base Catalyst for the Knoevenagel Condensation Reaction. Catalysis Letters. 141 (6): 877-881.

[20] Gupta, M., Gupta, R. and Anand, M. 2009. Hydroxyapatite Supported Cesium Carbonate as a Recyclable Solid Base Catalyst for the Knoevenagel Condensation in Water. Beilstein Journal of Organic Chemistry. 5: 68(1-7).

[21] Sugino, K., Oya, N., Yoshie, N. and Ogura, M. 2011. A Simple Modification Creates a Great Difference: New Solid-base Catalyst Using Methylated N-substituted SBA15. Journal of the American Chemical Society. 133(50): 20030-20032.

[22] Deng, Q. and Li, Q. 2018. Facile Preparation of Mg-doped Graphitic Carbon Nitride Composites as a Solid Base 
Catalyst for Knoevenagel Condensations. Journal of Materials Science. 53(1): 506-515.

[23] Ren, Y., Lu, J. X., Jiang, O., Cheng, X. and Chen, J. 2015. Amine-grafted on Lanthanide Metal-organic Frameworks: Three Solid Base Catalysts for Knoevenagel Condensation Reaction. Chinese Journal of Catalysis. 36(11): 1949-1956.

[24] Qiao, Y., Teng, J., Wang, S. and Ma, H. 2018. Aminefunctionalized Sugarcane Bagasse: A Renewable Catalyst for Efficient Continuous Flow Knoevenagel Condensation Reaction at Room Temperature. Molecules. 23(1): 43(113).

[25] Corma, A., Iborra, S., Primo, J. and Rey, F. 1994. One-step Synthesis of Citronitril on Hydrotalcite Derived Base Catalysts. Applied Catalysis A: General. 1 14(2): 215-225.

[26] Seto, H., Imai, K., Hoshino, Y. and Miura, Y. 2016. Polymer Microgel Particles as Basic Catalysts for Knoevenagel Condensation in Water. Polymer Journal. 48: 897-904.

[27] Almeida, K. A. and Cardoso, D. 2013. Basic Activity of Y Zeolite Containing Alkylammonium Cations in Knoevenagel Condensation. Catalysis Today. 213: 122126.

[28] Buasri, A., Chaiyut, N., Loryuenyong, V., Worawanitchaphong, P. and Trongyong, S. 2013. Calcium Oxide Derived from Waste Shells of Mussel, Cockle, and Scallop as the Heterogeneous Catalyst for Biodiesel Production. The Scientific World Journal. 2013: ID 460923, 7 pages. Doi: 10.1155/2013/460923

[29] Pena-Rodriguez, S., Bermudez-Couso, A., Novoa-Munoz, J. C., Arias-Estevez, M., Fernandez-Sanjurjo, M. J., AlvarezRodriguez, E., et al. 2013. Mercury Removal Using Ground and Calcined Mussel Shell. Journal of Environmental Sciences. 25(12): 2476-2486.

[30] El Haddad, M., Regti, A., Laamari, M. R., Slimani, R. Mamouni, R., El Antri, S., et al. 2014. Calcined Mussel Shells as a New and Eco-Friendly Biosorbent to Remove Textile Dyes from Aqueous Solutions. Journal of the Taiwan Institute of Chemical Engineers. 45(2): 533-540.

[31] Mar, W. W. and Somsook, E. 2012. Methanolysis of Soybean Oil over $\mathrm{KCl} / \mathrm{CaO}$ Solid Base Catalyst for Biodiesel Production. ScienceAsia. 38: 90-94.

[32] Boey, P., Maniam, G. P., Hamid, S. A. and Ali, D. M. H. 2011. Utilization of Waste Cockle Shell (Anadara granosa) in Biodiesel Production from Palm Olein: Optimization Using Response Surface Methodology. Fuel. 90(7): 23532358

[33] Suryaputra, W., Winata, I., Indraswati, N. and Ismadji, S. 2013. Waste Capiz (Amusium cristatum) Shell as a New Heterogeneous Catalyst for Biodieseil Production. Renewable Energy. 50: 795-799.

[34] Mardiana, L., Ardiansah, B., Septiarti, A., Bakri, R. and Kosamagi, G. 2017. Ultrasound-assisted Synthesis of Curcumin Analogs Promoted by Activated Chicken Eggshells. AIP Conference Proceedings. 1862: Article ID 030096. Doi: 10.1063/1.4991200

[35] Hu, K., Wang, H., Liu, Y. and Yang, C. 2015. KNO3/CaO as Cost-effective Heterogeneous Catalyst for the Synthesis of Glycerol Carbonate from Glycerol and Dimethyl Carbonate. Journal of Industrial and Engineering Chemistry. 28: 334-343.
[36] Mardiana, L., Ardiansah, B., Bakri, R., Cahyana, A. H. Anita, Y. and Aziza, N. P. 2017. Utilization of Eggshellderived Material as a Solid Base Catalyst for Efficien Synthesis of Substituted Chalcones. Jurnal Teknologi. 79(5): 175-182.

[37] Safaei-Ghomi, J., Ghasemzadeh, M. A and Mehrabi, M. 2013. Calcium Oxide Nanoparticles Catalyzed One-step Multicomponent Synthesis of Highly Substituted Pyridines in Aqueous Ethanol Media. Scientia Iranica. 20(3): 549-554.

[38] Mardiana, L., Bakri, R., Septiarti, L. and Ardiansah, B. 2017. The Synthesis of 2-(5-(3-methoxyphenyl)-4,5-dihydro-1Hpyrazol-3-yl)phenol using Sodium Impregnated on Activated Chicken Eggshells Catalyst. IOP Conference Series: Materials Science and Engineering. 188: Article ID 012022. Doi: 10.1088/1757-899X/188/1/012022.

[39] Patil, S., Jadhav, S. D. and Shinde, S. K. 2012. CES as an Efficient Natural Catalyst for Synthesis of Schiff Bases Under Solvent-free Conditions: An Innovative Green Approach. Organic Chemistry International. 2012: Article ID 153159 (5 pages). Doi: 10.1155/2012/153159.

[40] Mardiana, L., Ardiansah, B., Bakri, R. and Cahyana, H. 2016. Catalytic Activity of $\mathrm{Na}-\mathrm{CaO}$ Nanocrystalline for Vanillin-based Chalcone Syntheses. AIP Conference Proceedings. 1729: Article ID 020051. Doi: 10.1063/1.4946954

[41] Nurfitri, I., Pragas, G., Hindryawati, N. and Yusoff, M. M. 2013. Potential of Feedstock and Catalysts from Waste in Biodiesel Preparation: A Review. Energy Conversion Management. 74: 395-402.

[42] Won, Y.-H., Jang, H. S., Chung, D.-W. and Stanciu, L. A. 2010. Multifunctional Calcium Carbonate Microparticles: Synthesis and Biological Applications. Journal of Materials Chemistry. 20: 7728-7733.

[43] Ni, M. and Ratner, B. D. 2008. Differentiation of Calcium Carbonate Polymorphs by Surface Analysis Techniques An XPS and TOF-SIMS Study. Surface and Interface Analysis. 40(10): 1356-1361.

[44] Hayakawa, S., Hajima, Y., Qiao, S., Namatame, H. and Hirokawa, T. 2008. Characterization of Calcium Carbonate Polymorphs with $\mathrm{Ca} \mathrm{K}$ Edge X-ray Absorption Fine Structure Spectroscopy. Analytical Sciences. 24: 835-837.

[45] Tangboriboon, N., Kunanuruksapong, R. and Sirivat, A. 2012. Preparation and Properties of Calcium Oxide from Eggshells via Calcination. Materials Science-Poland. 30(4): 313-322.

[46] Geist, J., Auerswald, K. and Boom, A. 2005. Stable Carbon Isotopes in Freshwater Mussel Shells: Environmental Record or Marker for Metabolic Activity? Geochimica ef Cosmochimica Acta. 69(4): 3545-3554.

[47] Hu, S., Wang, Y. and Han, H. 2011. Utilization of Waste Freshwater Mussel Shell as an Economic Catalyst for Biodiesel Production. Biomass and Bioenergy. 35(8): 36273635.

[48] Xing, S., Li, J., Niu, G., Han, Q., Zhang, J. and Liu, H. 2018. Chiral and Amine Groups Functionalized Polyoxomethalate-based Metal-organic Frameworks for Synergic Catalysis in Aldol and Knoevenagel Condensation. Molecular Catalysis. 458: 83-88. 